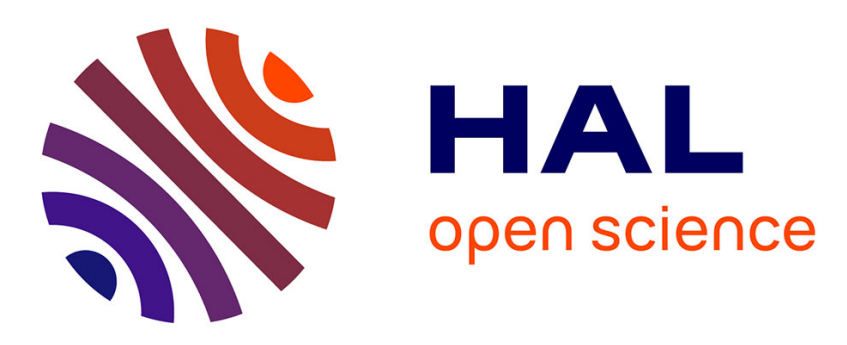

\title{
Sunglint observations over land from ground and airborne L-band radiometer data
}

Maria-José Escorihuela, Khaldoun Saleh, Philippe Richaume, Olivier Merlin, J. P. Walker, Yann H. Kerr

\section{- To cite this version:}

Maria-José Escorihuela, Khaldoun Saleh, Philippe Richaume, Olivier Merlin, J. P. Walker, et al.. Sunglint observations over land from ground and airborne L-band radiometer data. Geophysical Research Letters, 2008, 35 (20), pp.L20406. 10.1029/2008GL035062 . hal-00335847

\section{HAL Id: hal-00335847 https://hal.science/hal-00335847}

Submitted on 18 Aug 2021

HAL is a multi-disciplinary open access archive for the deposit and dissemination of scientific research documents, whether they are published or not. The documents may come from teaching and research institutions in France or abroad, or from public or private research centers.
L'archive ouverte pluridisciplinaire $\mathbf{H A L}$, est destinée au dépôt et à la diffusion de documents scientifiques de niveau recherche, publiés ou non, émanant des établissements d'enseignement et de recherche français ou étrangers, des laboratoires publics ou privés.

$$
\text { Copyright }
$$




\title{
Sunglint observations over land from ground and airborne L-band radiometer data
}

\author{
M. J. Escorihuela, ${ }^{1}$ K. Saleh, ${ }^{2}$ P. Richaume, ${ }^{3}$ O. Merlin, ${ }^{4}$ J. P. Walker, ${ }^{4}$ and Y. H. Kerr ${ }^{3}$ \\ Received 18 June 2008; revised 4 September 2008; accepted 15 September 2008; published 23 October 2008.
}

[1] This study quantifies the effects of Sun reflection over land surfaces on radiometric measurements at L-band. The impact of the reflected Sun on radiometric measurements over a grass field and over an agricultural area reached $25 \mathrm{~K}$ and $17 \mathrm{~K}$ respectively. A model that predicts the impact of Sun reflection over land is developed and tested for two different radiometer configurations and spatial resolutions. Citation: Escorihuela, M. J., K. Saleh, P. Richaume, O. Merlin, J. P. Walker, and Y. H. Kerr (2008), Sunglint observations over land from ground and airborne L-band radiometer data, Geophys. Res. Lett., 35, L20406, doi:10.1029/2008GL035062.

\section{Introduction}

[2] The Sun is an important emitter at L-band, with the Sun brightness temperature ranging from $100000 \mathrm{~K}$ up to several million Kelvin, depending on solar activity. Sun radiation can impact microwave remote sensing in different ways. Sunlight can get directly into the antenna or indirectly by reflecting over the different surfaces, thus increasing the overall brightness received by the radiometer.

[3] Soil moisture plays a key role in hydrological cycle. It is consequently a key variable in weather forecast models, climate studies, water resources, crop management, and forecasting extreme events. The best way to access to soil moisture is through the use of $\mathrm{L}$ band radiometry [Kerr, 2007]. In the near future two new satellite missions, the Soil Moisture and Ocean Salinity (SMOS) and the Soil Moisture Active Passive (SMAP) will be providing for the first time global mapping of surface soil moisture based on radiometric measurements at L-band. In the case of the SMOS (Soil Moisture and Ocean Salinity) mission [Kerr et al., 2001], Sun direct radiation will get directly into the instrument in approximately $96 \%$ of the images and cancelation techniques have already been developed [Camps et al., 2004]. The reflected Sun is located, by assuming a perfectly smooth surface, outside the SMOS useful field of view and consequently it should not be a problem. It is important, however, in order to evaluate remote sensing data at L-band the effects of sunglint be assessed.

[4] The effects of Sun reflection (or sunglint) over ocean have been the focus of several studies and Sun scattering models have been developed [Reul et al., 2007; Le Vine et $a l ., 2005]$. However, because of the low reflectivity of land

\footnotetext{
${ }^{1}$ Department of Hydrology and Water Resources, IsardSAT, Barcelona, Spain.

${ }^{2}$ Department of Geography, University of Cambridge, Cambridge, UK.

${ }^{3}$ Centre d'Etudes Spatiales de la Biosphère, Toulouse, France.

${ }^{4}$ Department of Civil and Environmental Engineering, University of Melbourne, Parkville, Victoria, Australia.

Copyright 2008 by the American Geophysical Union. 0094-8276/08/2008GL035062
}

surfaces, sunglint effects over land are expected to be much lower than over the ocean and no studies have addressed this issue at L-band.

[5] The aim of this paper is to (i) investigate the effects of Sun reflection over land surfaces and (ii) develop a simple model that predicts impact of Sun reflection on radiometric measurements at L-band. Two different datasets (SMOSREX and NAFE'06) and radiometer configurations (ground based and airborne respectively) are used. The SMOSREX experimental site allows investigation of sunglint effects at the field scale where the surface characteristics are well known. The NAFE experiment has monitored surfaces equivalent to a SMOS pixel, providing the unique opportunity to validate previous results at the SMOS scale.

\section{Sun Brightness Temperature}

[6] The Sun radio flux $\left(F_{\lambda}\right)$ is the brightness (at a certain wavelength $\lambda$ ) integrated over the entire solar disc. For Earth remote sensing, the solar disc is small (at L-band $\theta_{\text {Sun }}=$ $0.293^{\circ}$ ) and $F_{\lambda}$ can be approximated as:

$$
F_{\lambda}=B_{\lambda} \Omega_{\text {Sun }}
$$

where the mean brightness $B_{\lambda}$ is expressed in $\mathrm{Wm}^{-2} \mathrm{~Hz}^{-1} \mathrm{sr}^{-1}$ and $\Omega_{\text {Sun }}$ is the Sun solid angle as seen from the Earth:

$$
\Omega_{\text {Sun }}=2 \pi\left[1-\cos \theta_{\text {Sun }}\right]=8.2210^{-5} s r
$$

[7] Ground monitoring stations provide solar flux measurements at different wavelengths. The daily data (onesecond resolution) from the Radio Solar Telescope Network (RSTN) with observatories in Learmonth Australia 22S $114 \mathrm{E}$, and San Vito, Italy $41 \mathrm{~N} 18 \mathrm{E}$ were used in this study for the NAFE and SMOSREX analysis respectively.

[8] Assuming that the Sun is a blackbody, the Sun brightness temperature $\left(T_{\text {Sun }}\right)$ can be calculated using the Rayleigh-Jeans approximation [Le Vine et al., 2005]:

$$
T_{\text {Sun }}=\frac{\lambda^{2}}{2 k \Omega_{\text {Sun }}} F_{\lambda} 10^{-22}
$$

where $F_{\lambda}$ is expressed in solar flux units (sfu) $\left(1 \mathrm{sfu}=10^{-22}\right.$ $\mathrm{Wm}^{-2} \mathrm{~Hz}^{-1}$ ).

[9] The contribution to the antenna temperature due to the Sun radiation reflected on the land surface can be computed as:

$$
T_{a}=\frac{1}{\Omega_{a}} \int T_{S u n} \Gamma F_{n}(\Omega) d \Omega
$$


where $\Omega_{a}$ is the beam solid angle, $F_{n}$ is the normalized antenna pattern and $\Gamma$ is the surface reflectivity.

[10] The theoretical calculation requires the estimation of the surface reflectivity. In the case of land surfaces, simplified zero order radiative transfer equations are usually applied. The basic assumption is that, since the vegetation refraction index is close to that of the air, the reflectivity of the vegetation can be neglected. The scattering in the vegetation layer is thus not taken into account and only the contribution of scattering to energy loss is considered [Mo et al., 1982]. In this case, surface reflectivity can be calculated from brightness temperature measurements $\left(T_{B}\right)$ as:

$$
T_{B}=\left(1-\Gamma^{*}\right) T_{S}
$$

where $\Gamma^{*}$ is the effective surface reflectivity (which implicitly takes into account attenuation due to vegetation or surface roughness) and $T_{s}$ the surface temperature.

[11] In this study, the assumption that the standard deviation of surface height is small compared to the radiometer wavelength $(\lambda=21 \mathrm{~cm})$ is made (based on an assessment of surface roughness measurements). Thus scattering due surface roughness is also neglected and the Sun is reflected specularly on the field.

\section{Materials}

\subsection{SMOSREX Dataset}

[12] The SMOSREX experiment was designed to contribute to a better understanding of the different processes affecting the microwave signal at L-band in the context of the SMOS mission preparation. The experimental site is located in the South of France $\left(43^{\circ} 23 \mathrm{~N}, 1^{\circ} 18 \mathrm{E}\right)$, at an altitude of $188 \mathrm{~m}$. Since January 2003 SMOSREX has provided accurate field measurements of dual polarized L-band brightness temperature from a both bare soil and a fallow plot together with ground measurements of meteorological variables, soil moisture and temperature profiles. Further details concerning the SMOSREX experiment are provided by de Rosnay et al. [2006].

[13] The L-band radiometer for Estimating Water In Soils (LEWIS) is an L-band dual-polarized radiometer observing at a frequency of 1414 with $20 \mathrm{MHz}$ bandwidth. It is equipped with a $1.3 \mathrm{~m}$ diameter Potter horn antenna. The antenna pattern was measured in the Centre National d'Etudes Spatiales, Toulouse (France). The beam-width at $-3 \mathrm{~dB}$ is $13.6^{\circ}$, and the first side-lobes are at $-38 \mathrm{~dB}$. The calculated beam efficiency is greater than $98 \%$. The instrument resolution is $0.2 \mathrm{~K}$ for a $4 \mathrm{~s}$ integration time and the estimated accuracy of the calibration is $0.5 \mathrm{~K}$. The radiometer is thermally regulated to $0.02 \mathrm{~K}$ [Lemaitre et al., 2004].

[14] LEWIS is mounted on a 15 meter high structure centered on the experimental area. The grass field plot is situated south of the instrument. In this paper, continuous measurements of the grass field plot at $40^{\circ}$ incidence angle are used.

\subsection{NAFE'06 Dataset}

[15] The second National Airborne Field Experiment was conducted in South-Eastern Australia in November 2006. L-band microwave and infrared airborne measurements together with ground soil moisture and temperature were performed across three sites (Yanco, Kyeamba and Yenda) in the western part of the Murrumbidgee catchment. The NAFE'06 campaign primary ground verification focus was on six farms located in the $60 \times 60 \mathrm{~km}$ Yanco area. The Yanco soil moisture network includes 13 monitoring sites spatially distributed over the area. Landuse is mainly agricultural including dryland and irrigated cropping, pasture and grazing. The NAFE'06 experiment focused on practical applications for the SMOS mission, further details are provided by Walker et al. [2006] and Merlin et al. [2008].

[16] Radiometric measurements at L-band were performed with the Polarimetric L-band Multibeam Radiometer (PLMR). PLMR measures both $\mathrm{V}$ and $\mathrm{H}$ polarizations at a frequency of $1.413 \mathrm{GHz}$ with a bandwidth of $24 \mathrm{MHz}$. The PLMR antenna consists of an $8 \times 8$ array of dual polarized microstrip patches with two Butler beam-forming matrices providing six beams with pointing angles of $\pm 7, \pm 21.5$, \pm 38.5 degrees from nadir and a bandwidth of $14^{\circ}$ across track and $17^{\circ}$ along track [ProSensing, 2005]. PLMR antenna pattern is provided in the along and across axes, therefore an interpolated antenna pattern was used to estimate the gain at different incidence angles. The instrument can be mounted on the aircraft in either across track or along track configuration.

[17] PLMR flights were performed between 30th October and 20th November 2006. In this study, regional flights covering the entire Yanco area with the radiometer mounted in the across track configuration are used. The aircraft was flown at $3000 \mathrm{~m}$ height above the ground level providing data at $1 \mathrm{~km}$ spatial resolution. There is a one beam overlap between northward and southward PLMR ground track to ensure all the surface is covered and to allow for comparison between up/down flights. For this study, measurements performed by the outer overlapping radiometer beam in northward and southward flight lines are used.

\section{Sunglint Observations Over Land}

[18] In the SMOSREX experiment, radiometric measurements show a sudden increase of brightness temperature around midday, followed by a rapid decrease to values close to those in the morning. This fluctuation cannot be attributed to variations in parameters that affect the emission, such as vegetation water content, soil moisture or temperature. Consequently, the increase of brightness temperature measured by the radiometer is attributed to the Sun reflection over the grass field.

[19] The amplitude of the Sun reflection varies throughout the year and depends on the solar elevation. At the diurnal scale, maximum Sun reflection occurs at noon when the Sun is exactly in the azimuth measuring direction of LEWIS. The impact of solar reflection on radiometric measurements is maximum when the Sun and the radiometer are aligned both in zenith and azimuth, which occurs at noon close to the solar equinox. When close to the solstices (winter or summer) the impact of Sun in radiometric measurements is minimum and reaches about $2 \mathrm{~K}$ at noon. When close to the solar equinox, the increase in brightness temperature due to solar reflection on the grass can reach $25 \mathrm{~K}$ (depending on the reflectivity). 

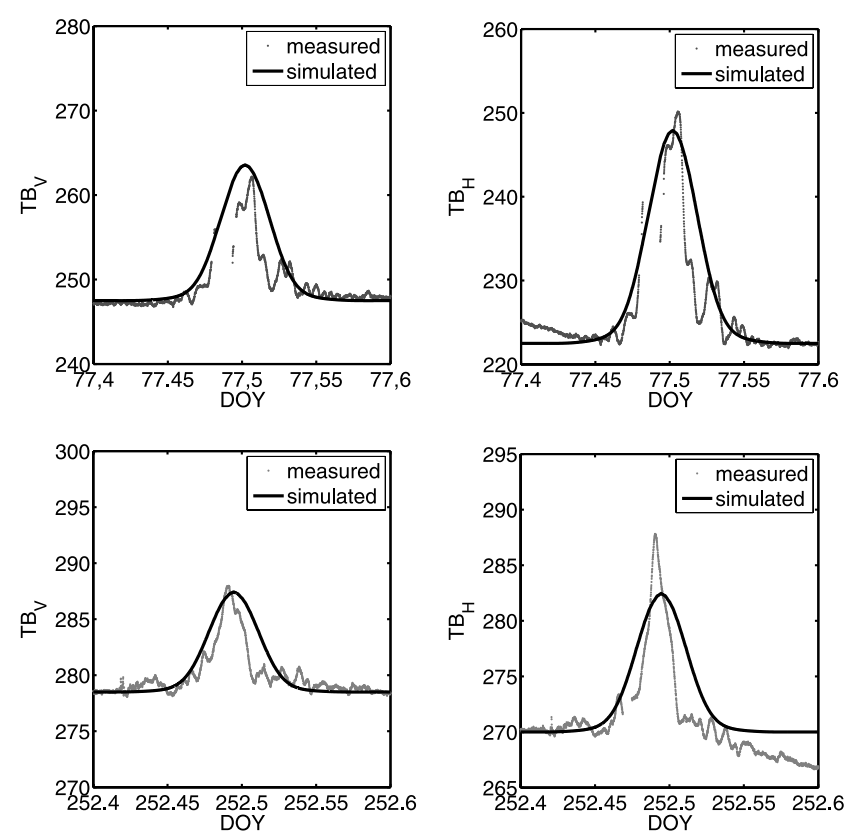

Figure 1. Impact of Sun reflection on DOY 77 and DOY 252 on SMOSREX site. For each date, measured and simulated vertical and horizontal polarized brightness temperature are provided.

[20] The impact of Sun reflection at the SMOSREX field was simulated by using equations (3) and (4). The surface reflectivity $\left(\Gamma_{p}\right)$ was estimated by using the averaged polarized brightness temperature and surface temperature before and after Sun reflection in equation (5).

[21] The effects of Sun reflection for two arbitrarily chosen days during the year are shown in Figure 1. For each plot the theoretical calculation of the impact of the Sun is also plotted. The following values were used in the calculation of the surface reflectivity on DOY $77, T B_{V}=$ 247.5, $T B_{H}=222.5$ and $T_{s}=290$ and on DOY $252 T B_{V}=$ $278.5, T B_{H}=270$ and $T_{s}=300$.

[22] The agreement between measurements and simulations is very good in terms of the duration and amplitude of the Sun effects. Should vegetation or soil roughness scattering play a role, measured Sun effects will spread over a wider time span than those simulated by the specular model.
This is not the case here, actually measured effect seem to be somewhat narrower than the simulated one, which validates the hypothesis of specular reflection. However, measurements exhibit a more fluctuating behaviour than the simulations. The fluctuation pattern is different between non consecutive days although it is very similar in consecutive days (not shown). Thus it cannot be attributed to the antenna pattern (whose effect remains constant) or variations of $T_{\text {Sun }}$ (very similar fluctuation pattern on DOY 77, DOY 78 and DOY 79). A constant value of reflectivity, derived from radiometer data, is used to calculate the impact of Sun reflection. However, because of the differences in solid angle between the Sun $\left(\theta_{\text {Sun }}=0.293^{\circ}\right)$ and the radiometer $\left(\theta_{r}=13^{\circ}\right)$, the surface that contributes to Sun reflection is smaller than that seen by the radiometer. Consequently, the Sun scans the surface reflectivity at a higher spatial resolution than the radiometer. Soil moisture and vegetation heterogeneity within the radiometer FOV, and a nonconstant reflectivity as a result, could explain the fluctuating behaviour of measurements. Apart from the oscillating behaviour, this simple model provides a good estimation of the effects of Sun reflection on radiometric measurements. This model is next tested with the NAFE dataset.

[23] During the NAFE'06 experiment the effects of sunglint clearly show up as lines with higher than average brightness temperature in Regional flights performed on November 13th, 14th and 16th by Merlin et al. [2008, Figure 2], despite the relative position between the Sun and antenna not being optimal for sunglint to occur.

[24] To quantify sunglint effects, the brightness temperature of the outer overlapping radiometer beam in northward and southward flight lines are compared. The overlapping ground tracks are observed at the same incidence angle $(\theta)$ but the relative azimuth to the Sun changes by $180^{\circ}$ between northward and southward lines. The brightness temperature of the outer right beam (3R) for northward and southward lines as a function of the latitude is shown for November 14th in Figure 2. The Sun position changes during measurements; at the beginning of measurements $(11 \mathrm{~h} 30 \mathrm{LT})$, the Sun position is $\phi_{\text {Sun }}=0 \theta_{\text {Sun }}=16$, while at the end of measurements (13h30 LT), the Sun position is $\phi_{\text {Sun }}=304$ and $\theta_{\text {Sun }}=26$.

[25] During northward flights, the radiometer is oriented in such a way (i.e. the relative azimuth to the Sun is large) that the Sun reflection is out of the field of view. Measured
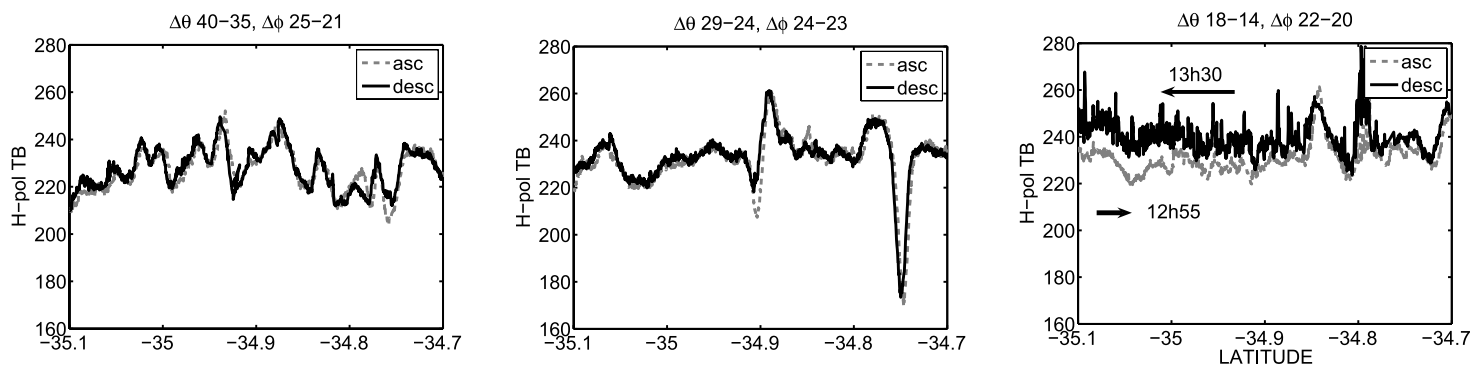

Figure 2. Horizontal polarized brightness temperature of 3R-beam during Yanco Regional flights for northward and southward flights on November 14th as a function of the latitude. Three different overlapping flight lines are shown. The angular difference in zenith $(\Delta \theta)$ and azimuth $(\Delta \phi)$ between the Sun and the radiometer decreases during the flight time and is also provided. 


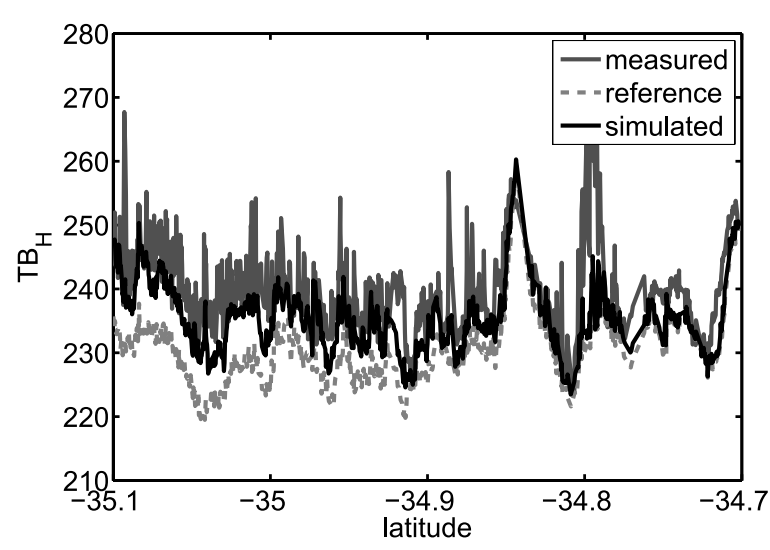

Figure 3. Comparison between measured and simulated Sun effects during the NAFE experiment. Measurements were performed on November 14th during the third flight line.

brightness temperature is thus not affected by Sun reflection and can be used as a reference. During the first and second southward lines, the difference in zenith $(\Delta \theta)$ decreases from 40 to $24^{\circ}$ and the azimuth difference $(\Delta \phi)$ from 25 to $21^{\circ}$. The Sun reflection is therefore outside the main lobe of the radiometer and both overlapping brightness temperatures (northward and southward) compare well (see first and middle second in Figure 2. During the third southward line, the difference between the Sun and the antenna zenith $\Delta \theta$ decreases from 18 to $14^{\circ}$ and in azimuth from $\Delta \phi=22$ to $20^{\circ}$. Consequently, the impact of the reflected Sun in radiometric measurements (and the difference between northward and southward lines) increases with time as it is clearly shown in the third panel in Figure 2 (note that for the southward flights the latitude decreases with time).

[26] The impact of the reflected Sun on the measured brightness temperature depends basically on the Sun temperature, the surface reflectivity and the antenna gain. The aircraft pitch, roll and heading changes slightly as the aircraft moves and therefore the gain at which the antenna 'sees' the Sun changes with time. Because of the high value of $T_{\text {Sun }}$, those slight differences in gain and reflectivity as the aircraft moves translate into a 'noisy' brightness temperature in the southward line. The averaged increase in brightness temperature at $\mathrm{H}-\mathrm{pol}$ is $17 \mathrm{~K}$ and at V-pol is $7 \mathrm{~K}$.

[27] The effects of Sun reflection were simulated for the 14th November flight. For a given latitude, the radiometric measurement from the northward flightline was used to estimate surface reflectivity and as reference brightness temperature. A constant value of $T_{s}=300$ was considered. The comparison between model and observed brightness temperature is shown in Figure 3. The model predicts well the increase of brightness temperature although there is in general a slight underestimation. Two approximations used in the calculation of the reflected brightness temperature could lead to underestimated brightness temperature. First, the antenna pattern multiplies directly $T_{\text {Sun }}$ (see equation (4)) and thus a slight error in the antenna gain has an impact in the calculation of the reflected brightness temperature. Second, the reference temperature might increase from northward (at 12h55) to southward flights (at 13h30).
Similarly to the SMOSREX case, measurements exhibit a more oscillating behaviour than predicted by the model. Because of the coarser spatial resolution of the airborne radiometer $\left(1 \mathrm{~km}^{2}\right)$ when compared to the ground radiometer $\left(20 \mathrm{~m}^{2}\right)$, heterogeneity within the radiometer field of view is expected to have a higher impact than at the field scale and can partly explain the fluctuating behaviour of measurements.

\section{Conclusions}

[28] L-band radiometric measurements performed during SMOSREX and NAFE'06 experiment were used to evaluate the impact of Sun reflection over land surfaces. The use of two different data sets allowed evaluation of the impact of Sun reflection over land at two different scales (field and regional).

[29] In the SMOSREX field experiment, Sun reflected on the grass field increased the brightness temperature by 2 to $25 \mathrm{~K}$ depending on the Sun-radiometer angular configuration. During the NAFE'06 airborne campaign, the Sun impact on radiometric measurements was easily observable and appeared as lines of higher than average brightness temperature. For a zenith angular difference of $14^{\circ}$, and an azimuth angular difference of $20^{\circ}$ between the radiometer and the Sun, the averaged increase in brightness temperature at $\mathrm{H}$-pol and V-pol was $17 \mathrm{~K}$ and $7 \mathrm{~K}$ respectively over an agricultural area.

[30] A simple model was developed to estimate the impact of Sun reflection. This model considered specular reflection on the land surface, by assuming the scattering effect of vegetation and soil roughness negligible. This model predicted well the amplitude of the impact of Sun reflection. However the observations exhibited a more fluctuating behaviour than simulations. The fluctuating behaviour of measurements is attributed to soil moisture and vegetation heterogeneity within the radiometer field of view.

[31] Acknowledgments. M. J. Escorihuela thanks the Bureau of Meteorology in Melbourne and specially Peter Steinle for hosting her for three months. The authors thank Joe Tenerelli and Nicolas Reul for developing the TRAP software that allows the calculation of the relative zenith and azimuth angles between the Sun and the radiometer. The National Airborne Field Experiment was funded by Australian Research Council Discovery Project DP0557543.

\section{References}

Camps, A., M. Vall-llossera, N. Duffo, M. Zapata, I. Corbella, F. Torres, and V. Barrena (2004), Sun effects in 2-D aperture synthesis radiometry imaging and their cancelation, IEEE Trans. Geosci. Remote Sens., 42, $1161-1167$.

de Rosnay, P., et al. (2006), SMOSREX: A long term rield campaign experiment for soil moisture and land surface processes remote sensing, Remote Sens. Environ., 102, 377-389.

Kerr, Y. (2007), Soil moisture from space: Where we are?, Hydrogeol. J., 15, 117-120.

Kerr, Y., P. Waldteufel, J-.P. Wigneron, J-.M. Martinuzzi, J. Font, and M. Berger (2001), Soil moisture retrieval from space: The soil moisture and ocean salinity (SMOS) mission, IEEE Trans. Geosci. Remote Sens., 39, 17291735 .

Lemaître, F., J. Poussiere, Y. Kerr, M. Dejus, R. Durbe, P. de Rosnay, and J. Calvet (2004), Design and test of the ground based L-band radiometer for estimating water in soils (LEWIS), IEEE Trans. Geosci. Remote Sens., 42, 1666-1676.

Le Vine, D., S. Abraham, F. Wentz, and G. Lagerloef (2005), Impact of the Sun on remote sensing of sea surface salinity from space, Atmos. Res., 87, $288-291$.

Merlin, O., et al. (2008), The NAFE'06 data set: Towards soil moisture retrieval at intermediate resolution, Adv. Water Res., in press. 
Mo, T., B. Choudhury, T. Schmugge, J. Wang, and T. Jackson (1982), A model for microwave emission from vegetation-covered fields, J. Geophys. Res., 87, 11,229-11,237.

ProSensing (2005), Polarimetric L-band Multi-beam Radiometer (PLMR) technical report, Amherst, Mass.

Reul, N., J. Tenerelli, B. Chapron, and P. Waldteufel (2007), Modeling Sun glitter at L-band for sea surface salinity remote sensing with SMOS, IEEE Trans. Geosci. Remote Sens., 45, 2073-2087.

Walker, J., O. Merlin, and R. Panciera (2006), National Airborne Field Experiment 2006 (NAFE’06): Experiment plan, Univ. of Melbourne,
Parkville, Victoria, Australia. (Available at http://www.nafe.unimelb. edu.au)

M. J. Escorihuela, Department of Hydrology and Water Resources, IsardSAT, Barcelona, Spain. (mj.escorihuela@isardsat.cat)

O. Merlin and J. P. Walker, Department of Civil and Environmental Engineering, University of Melbourne, Parkville, Vic 3010, Australia.

P. Richaume and Y. H. Kerr, Centre d'Etudes Spatiales de la Biosphère, F-31401 Toulouse CEDEX 9, France.

K. Saleh, Department of Geography, University of Cambridge, Cambridge CB2 3EN, UK. 